\title{
Interest and Attitudes of Medical, Dental Students and Graduates Towards Pursuing Career in Basic Sciences
}

\author{
Emal Heer, Sohail Saadat, Omaima Anis Bhatti \\ $------------------------------------$ \\ ABSTRACT
}

Objectives: To assess attitudes and perception of medical as well as dental students and graduates about a career in basic sciences from a public sector institute of Karachi.

Study design and setting: A cross-sectional survey carried out using an online questionnaire amongst medical and dental final year students and graduates from Dow University of Health Sciences, Karachi, Pakistan.

Methodology: Data collected was analyzed using SPSS version 24.0. Chi-square test was used to compare categorical variables with likert scale responses regarding attitudes and perceptions about a career in basic sciences.

Results: Out of 315 participants, $41.3 \%$ showed interest in basic sciences career. $46.4 \%$ of graduates showed interest in basic sciences compared to $15.4 \%$ of students. Chi-square test did not reveal any significant association between medical and dental students and graduates and their attitudes and perceptions regarding a career in basic sciences.

Conclusion: Overall, a more positive response towards basic sciences was observed in our study, with graduates reported being more attracted to a basic sciences career than students. However, majority believed there is lack of motivation and awareness about this career path, limited career and post-graduation options in basic sciences, no patient interaction and pressure from family creates disinterest in this career.

Keywords: Attitudes, Basic science career, Medical and Dental, Students.

How to cite this Article:

Heer E, Saadat S, Bhatti OA. Interest and Attitudes of Medical, Dental Students and Graduates Towards Pursuing Career in Basic Sciences. J Bahria Uni Med Dental Coll. 2021; 11(4):168-173 DOI: https://doi.org/ 10.51985/JBUMDC2021053

This is an Open Access article distributed under the terms of the Creative Commons Attribution Non Commercial License (http:// creativecommons/org/licences/by-nc/4.0) which permits unrestricted non commercial use, distribution and reproduction in any medium, provided the original work is properly cited.

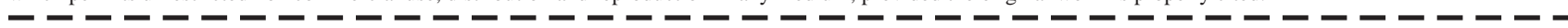

\section{INTRODUCTION:}

Basic sciences build the foundation for understanding clinical teaching and learning. ${ }^{1}$ In Pakistan, Basic Medical Science subjects such as Anatomy, Physiology, Biochemistry, Pharmacology, Pathology and Microbiology are taught at an undergraduate level in the five-year and four-year curriculum of Bachelors of Medicine and Bachelor of Surgery (MBBS) and Bachelors of Dental Surgery (BDS), respectively. Additionally, Basic Dental Science subjects such as Oral Biology and Tooth Morphology, Oral Pathology, Community Dentistry and Science of Dental Materials are taught in preclinical years of BDS.

I Emal Heer
I Demonstrator/Lecturer, Department of Pharmacology
I Dr. Ishrat-ul-Ebad Khan Institute of Oral Health Sciences,
I Dow University of Health Sciences
Email: emalbhatti@gmail.com
I Sohail Saadat
I Assistant Professor, Department of Community Dentistry, |
I Dr. Ishrat-ul-Ebad Khan Institute of Oral Health Sciences,
I Dow University of Health Sciences
I Omaima Anis Bhatti
I Student of 4th Year MBBS
I Aga Khan University
I Received: 02-Sep-2021
I Accepted: 28-Sep-2021

Deciding a future career path is an important yet complicated task especially for medical and dental students. An individual's inclination toward a particular career depends on various factors coupled with awareness and attitude towards different pathways in their field of study. ${ }^{2}$ For a medical graduate, future certainty, good earning and a better working environment direct the preference for a career path. ${ }^{3}$ Furthermore, rotating in different specialties during their time in medical school help students decide a career path in a particular specialty after graduation. ${ }^{4}$ Basic sciences can be opted as a potential career rather than just a prerequisite to get promoted to clinical years, a concept that needs reinforcement amidst students. ${ }^{5}$ Career options after graduating from a medical school initially fall into two broad categories, namely clinical sciences and basic sciences. ${ }^{6}$

It has been observed that students become more averse to basic sciences as they progress through medical school, ${ }^{7}$ resulting in graduates distributing unevenly throughout different medical specialties leading to shortage in one field and overload in an other ${ }^{8,9}$ Medical students of Juntendo University School of Medicine in Tokyo, Japan reported a $24.5 \%$ rate of interest in basic sciences and considered it as one of their career paths, They also described the shortage of teaching faculty required in basic sciences and are working on it to alleviate this problem. ${ }^{10}$ 
Another study found that only $10 \%$ of third-year MBBS students in a medical college in Lahore, Pakistan, were interested in basic medical sciences. Therefore, reasons for lack of inclination towards basic sciences in our region also need to be explored. While several studies have been conducted on MBBS students showing lack of interest in basic sciences and considering it as a career option, there is little information available about the perspectives of medical and dental students and graduates regarding it. Therefore, the objective of this study was to assess the interests attitudes and perceptions of medical as well as dental students and graduates towards pursuing a career in basic sciences from a public institution in Karachi, Pakistan,

\section{METHODOLOGY:}

This cross-sectional survey was carried out amongst medical and dental final year students and graduates including house officers from four medical and three dental constituent colleges of Dow University of Health Sciences, a public sector university in Karachi, Pakistan, regarding their attitudes and perception about a career in basic sciences. Approval from Institutional Review Board of Dow University of Heath Sciences was taken before the start of study [Ref: IRB1815/DUHS/Approval/2020] dated $1^{\text {st }}$ December, 2020. Objective of the study was explained in questionnaire, consent of participation and assurance of confidentiality of all the information provided was acknowledged. Participants were allowed to refuse or withdraw from study at any time.Final year students and graduates within 5 years of graduation were chosen. Respondents who provided incomplete responses were excluded. Sample size was calculated using an Open Epi calculator. The proportion of considering basic sciences as a career path was $23.0 \%$ among medical students according to Y.Yamazaki et al. ${ }^{10}$ With 5\% margin of error and $95 \%$ confidence level, the total estimated sample size came out to be 273 . A self-designed questionnaire was made using Google docs, adopted from a study conducted at a medical school in Tokyo, Japan ${ }^{10}$. After the approval from Institutional Review Board, study tool questionnaire was applied to $30 \%$ of total sample size $(n=80)$ for the purpose of validation. Cronbach's Alpha was used to evaluate internal consistency of the questionnaire which was within an acceptable range (0.644). After validation of the questionnaire, participants who fulfilled the inclusion criteria were contacted through social media (eg: WhatsApp, Instagram, Gmail, Facebook) and were asked to fill out an online questionnaire with informed consent.

Questionnaire consisted of 3 sections; 1: basic demographic details, 2: interest/disinterest in pursuing a career in basic sciences, which consisted of three sub headings as follows: a) interest in basic sciences as a career option, b) reasons of interest in basic sciences and c) reasons of disinterest in basic sciences and 3: a 5 point Likert scale questions ranging from "strongly agree "to "strongly disagree" on attitudes and perception about a career in basic sciences. Responses were analyzed first which were later merged (strongly agree/agree $=1$, neutral $=2$, strongly disagree/disagree $=3$ )Table 1. Data collected was entered and analyzed using SPSS version 24.0. Frequencies of categorical variables and multiple responses were calculated. Chi-square test was used to compare categorical variables with Likert scale responses regarding attitudes and perceptions about a career in basic sciences and interest in basic sciences. P-value of $<0.05$ was considered significant. Results were presented using tables and figures.

\section{RESULTS:}

A total of 316 individuals responded to the questionnaire, out of which one participant was excluded from study for not fulfilling the inclusion criteria. Demographic details of participants were shown in Table 1. Mean age of participants was $25.37 \pm 2.150$. Ratio of females and dentists/dental students who responded were more than medical students and males, as study design was convenience sampling, results made were according to questionnaires returned by the population Interest in Basic Sciences as a career option: Overall, a total of $130(41.3 \%)$ participants showed interest in basic sciences as a career option while $120(38.1 \%)$ showed no interest and $65(20.6 \%)$ were not sure about it (Table.1). Reasons of interest and disinterest are shown in Table 1. Chi-square test was applied between categorical variables and their interest in basic sciences as a career option. Educational level and marital status had a significant association with interest in basic sciences, out of all graduates, $46.4 \%$ showed interest whereas amongst final year students only $15.4 \%$ of students showed interest in basic science career from both disciplines MBBS and BDS respectively (p-value: 0.001). Similarly, out of all married individuals, $47.5 \%$ showed interest in basic science career that was slightly higher than those who were single $37.4 \%$ (p-value: 0.032 ). Gender, professional qualification, and employment status did not significantly influence the interest towards choosing a career in basic sciences (p-values: 0.586, 0.171 and 0.472 respectively) (Table.2) Attitudes and perception about a career in Basic Sciences: Chi square test was used to compare different variables with relevant Likert scale questions regarding their attitudes and perception about a career in basic sciences. Chi square test did not reveal any significant difference as any level of education or graduation, employment status, gender, field of study or marital status did not impact their attitudes and perceptions towards a career in basic sciences. Almost similar agreement responses among both medical and dental students and graduates were observed. Majority of students and graduates agreed to statements regarding a perception that "There is a lack of awareness amongst medical students/graduates regarding basic sciences as a career option" ( $\mathrm{p}$-value $=0.092$ ), also that "There are limited post-graduation or employment options in basic sciences" and "lack of motivation for pursuing career in basic sciences due to no patient interaction and 
Emal Heer, Sohail Saadat, Omaima Anis Bhatti

Table.1. Attributes of participants $(\mathrm{n}=315)$

\begin{tabular}{|c|c|c|c|}
\hline Demographics & & $\mathbf{N}$ & $\%$ \\
\hline \multirow{2}{*}{ Gender } & Male & 52 & 16.5 \\
\hline & Female & 263 & 83.5 \\
\hline \multirow{3}{*}{ Age } & $21-23$ & 78 & 24.8 \\
\hline & $24-26$ & 131 & 41.6 \\
\hline & $27-29$ & 106 & 33.6 \\
\hline \multirow{2}{*}{ Professional qualification } & MBBS & 110 & 34.9 \\
\hline & BDS & 205 & 65.1 \\
\hline \multirow{4}{*}{ Current educational level } & Final year student & 52 & 16.5 \\
\hline & Medical house officer & 18 & 5.7 \\
\hline & Dental house officer & 55 & 17.5 \\
\hline & Graduated done with house job & 190 & 60.3 \\
\hline \multirow{5}{*}{$\begin{array}{l}\text { Current position after } \\
\text { graduation }\end{array}$} & House officer & 69 & 21.9 \\
\hline & Post graduate trainee & 43 & 13.7 \\
\hline & Employed & 91 & 28.9 \\
\hline & Unemployed & 60 & 19 \\
\hline & Not applicable & 52 & 16.5 \\
\hline \multirow{2}{*}{ Marital status } & Single & 195 & 61.8 \\
\hline & Married & 120 & 38.1 \\
\hline \multicolumn{4}{|c|}{ Interest/Disinterest in pursuing a career in basic sciences } \\
\hline & & $\mathrm{N}$ & $\%$ \\
\hline \multirow{3}{*}{$\begin{array}{l}\text { Interest in basic sciences } \\
\text { as career option }\end{array}$} & Yes & 130 & 41.3 \\
\hline & No & 120 & 38.1 \\
\hline & Not sure & 65 & 20.6 \\
\hline \multirow{5}{*}{$\begin{array}{l}\text { Reasons of interest in } \\
\text { Basic sciences } \\
\text { (multiple responses) }\end{array}$} & I am interested in research & 53 & 27.5 \\
\hline & I am interested in teaching and/or non-clinical job & 45 & 23.3 \\
\hline & Better balance between work and life & 54 & 28 \\
\hline & Better working place/environment and/or working hours & 34 & 17.6 \\
\hline & No particular reason & 7 & 3.6 \\
\hline \multirow{6}{*}{$\begin{array}{l}\text { Reasons of disinterest in } \\
\text { Basic Sciences } \\
\text { (multiple responses) }\end{array}$} & I entered medical college to become a clinical practitioner & 117 & 52 \\
\hline & I am not interested in pursuing a career in basic sciences & 45 & 20 \\
\hline & I am not interested in academia related career & 29 & 12.9 \\
\hline & Basic sciences won't pay me enough & 9 & 4 \\
\hline & Family/peer pressures & 7 & 3.1 \\
\hline & No particular reason & 18 & 8 \\
\hline
\end{tabular}

Table-2. Comparison between variables and Interest in basic sciences or research as career option

\begin{tabular}{|l|l|c|c|c|c|}
\hline \multicolumn{2}{|c|}{ Variables } & $\begin{array}{c}\text { No } \\
(\mathbf{n} / \%)\end{array}$ & $\begin{array}{c}\text { Yes } \\
(\mathbf{n} / \%)\end{array}$ & $\begin{array}{c}\text { Not sure } \\
(\mathbf{n} / \%)\end{array}$ & \multirow{2}{*}{ P-value } \\
\hline \multirow{2}{*}{ Gender } & Male & $23(44.2)$ & $20(38.5)$ & $9(17.3)$ & \multirow{2}{*}{0.586} \\
\cline { 2 - 5 } & Female & $97(36.9)$ & $110(41.8)$ & $56(21.3)$ & \\
\hline \multirow{2}{*}{ Professional qualification } & MBBS & $49(44.5)$ & $43(39.1)$ & $18(16.4)$ & \multirow{2}{*}{0.171} \\
\cline { 2 - 5 } & BDS & $71(34.6)$ & $87(42.4)$ & $47(22.9)$ & \\
\hline \multirow{2}{*}{ Current educational level } & Final year students & $27(51.9)$ & $8(15.4)$ & $17(32.7)$ & \multirow{3}{*}{0.001} \\
\cline { 2 - 5 } & Graduates & $93(35.4)$ & $122(46.4)$ & $48(18.3)$ & \multirow{2}{*}{0.472} \\
\hline \multirow{2}{*}{ Current position after graduation } & Employed & $72(35.5)$ & $91(44.8)$ & $40(19.7)$ & \\
\cline { 2 - 5 } & Unemployed & $21(35.0)$ & $31(51.7)$ & $8(13.3)$ & \\
\hline \multirow{2}{*}{ Marital status } & Single & $73(37.4)$ & $73(37.4)$ & $49(25.1)$ & \multirow{2}{*}{$0.032 *$} \\
\cline { 2 - 5 } & Married & $47(39.2)$ & $57(47.5)$ & $16(13.3)$ & \\
\hline
\end{tabular}


Interest and Attitudes of Medical, Dental Students and Graduates Towards Pursuing Career in Basic Sciences

Table 3. Attitudes and perception of medical and dental students and graduates about a career in basic sciences $\left(?^{2}\right.$ test $)$

\begin{tabular}{|c|c|c|c|c|c|}
\hline Statement & & Agree & Neutral & Disagree & p-values \\
\hline \multirow{2}{*}{$\begin{array}{l}\text { There is a lack of awareness amongst medical students/graduates } \\
\text { regarding basic sciences a career option }\end{array}$} & MBBS & $100(90.9 \%)$ & $4(3.6 \%)$ & $6(5.5 \%)$ & \multirow{2}{*}{0.092} \\
\hline & $\overline{B D S}$ & $173(84.4 \%)$ & $22(10.7 \%)$ & $10(4.9 \%)$ & \\
\hline \multirow{2}{*}{$\begin{array}{l}\text { There are limited post-graduation or employment options in basic } \\
\text { sciences }\end{array}$} & MBBS & $75(68.2 \%)$ & $27(24.5 \%)$ & $8(7.3 \%)$ & \multirow{2}{*}{0.418} \\
\hline & BDS & $154(75.1 \%)$ & $39(19.0 \%)$ & $12(5.9 \%)$ & \\
\hline \multirow{2}{*}{$\begin{array}{l}\text { There is a lack of motivation to pursue career in basic sciences because } \\
\text { of no patient interaction and little use of medical training }\end{array}$} & MBBS & $86(78.2 \%)$ & $20(18.2 \%)$ & $4(3.6 \%)$ & \multirow{2}{*}{0.090} \\
\hline & BDS & $179(87.3 \%)$ & $20(9.8 \%)$ & $6(2.9 \%)$ & \\
\hline \multirow{2}{*}{$\begin{array}{l}\text { Basic science research is not as well recognized and not given enough } \\
\text { importance as clinical research }\end{array}$} & MBBS & $80(72.7 \%)$ & $22(20.0 \%)$ & $8(7.3 \%)$ & \multirow{2}{*}{0.853} \\
\hline & BDS & $155(75.6 \%)$ & $37(18.0 \%)$ & $13(6.3 \%)$ & \\
\hline \multirow{2}{*}{$\begin{array}{l}\text { There a lack of encouragement for pursuing basic sciences by teachers } \\
\text { and medical community around you }\end{array}$} & MBBS & $82(74.5 \%)$ & $21(19.1 \%)$ & $7(6.4 \%)$ & \multirow{2}{*}{1.000} \\
\hline & BDS & $153(74.6 \%)$ & $39(19.0 \%)$ & $13(6.3 \%)$ & \\
\hline \multirow{2}{*}{$\begin{array}{l}\text { Pressure from family and society makes most students choose clinical } \\
\text { career path }\end{array}$} & MBBS & $70(63.6 \%)$ & $27(24.5 \%)$ & $13(11.8 \%)$ & \multirow{2}{*}{0.294} \\
\hline & BDS & $114(55.6 \%)$ & $55(26.8 \%)$ & $36(17.6 \%)$ & \\
\hline
\end{tabular}

little use of medical training" (p-value $=0.418$ and 0.090 respectively). They also perceived that basic science research is not as recognized and given importance as clinical research ( $\mathrm{p}$ value $=0.853$ ), "pressure from society makes most students choose clinical path" ( $p$-value $=0.294$ ) and "There a lack of encouragement for pursuing basic sciences by teachers and medical community around you" (p-value: 1.000) (Table.3).

\section{DISCUSSION:}

Career in basic medical and dental sciences mainly revolves around academic teaching and research. Moreover, basic science research ultimately paves the way for thoroughly understanding and reforming clinical medicine and practice for the well-being of patients. ${ }^{11}$ A study conducted in an Australian critical care unit stressed the importance of basic science research in clinical practice, where $74 \%$ of health professionals concluded that basic sciences holds a significant impact on clinical diagnosis. ${ }^{12}$ Medical graduates find clinical sciences more attractive than basic sciences because there is a general perception that it offers a more secure and profitable job, on the other side, students avoid opting for basic sciences as they believe it may narrow down their skills to teaching only without any clinical development. ${ }^{13}$ To reinforce this, a study in Nepal concluded that only $9 \%$ of students preferred basic sciences for post-graduation. ${ }^{5}$

Previous studies conducted at an undergraduate level and few among house officers of various medical colleges of Pakistan and abroad revealed a basic sciences career being least preferred by medical students. ${ }^{5,9,10}$ This study, however, focused on final year students along with graduates including house officers up to five years of their graduation from both medical and dental backgrounds. Final year students and graduates within 5 years of graduation were chosen as they have understanding of both basic and clinical sciences and they still remain undecided about their career $^{3}$, with four medical colleges and three dental colleges affiliated with Dow University of Health Sciences, Karachi, Pakistan participating in the study. Overall, a more positive response towards basic sciences was observed in this study. Total 41.3\% participants showed interest in basic science career which was comparatively higher than the studies conducted previously. For example, a similar study with contrasting results carried out at Dow International Medical College, Karachi, Pakistan, showed only $4.1 \%$ of medical students choosing basic sciences as a preference for a prospective career. ${ }^{14}$

In this study, graduates reported being more attracted to a basic science career than students. In a study conducted amongst final years and graduates (house officers) in Karachi, Pakistan, both groups showed no significant difference in choosing a career specialty, contrasting to this study where a larger sample of graduates was taken, and seemed to be more interested in basic sciences as compared to students. ${ }^{15}$ One explanation to this could be that after graduation many students get more exposed to different specialties during house-job which might influence their choices, since they get to experience the clinical workload more closely. Secondly, country like Pakistan; there are limited seats in every post graduate program specially in dental medicine, along with a decreased passing ratio of post graduate exams and high saturation and competitiveness in employment in clinical fields, which might result in graduates being more inclined towards other specialties such as basic sciences. ${ }^{16}$ Deducing from this study, married individuals showed more interest in basic science career, which could be result of prioritizing their family along with receiving a stable income and a better lifestyle which might lead to more preference for this specialty.

Studies suggest career counseling for medical students is imperative, as many students despite being exposed to every specialty still remained doubtful at the end of their undergraduate school. ${ }^{17}$ However, it can be deduced from our findings that career related decisions may get defined 
years past graduation as well and studies should not be limited to the student level only. Career choice is driven by an array of factors which leads to a final decision. One such factor is a promising lifestyle with a better work life balance along with flexibility in timings, which comes with a basic sciences job. ${ }^{18}$ On the other hand, the desire of becoming a clinician proves to be a demotivating factor for a basic sciences profession. It has been seen that no patient interaction leads to decreased interest and motivation towards a basic sciences career. ${ }^{19}$ Secondly, in this study only $3 \%$ considered pressure from family as a reason for disinterest in basic sciences, which is consistent with the results of another study where dental students perceived enforcement from family least important factor deciding a career. ${ }^{20}$ However, on a larger scale, societal and family pressure does play a very influential role in deciding career paths in this part of the world, as clinicians are held in the highest regard and a basic sciences job is considered less important in society. This perception needs to change in the society as a whole, since basic sciences contribute heavily to evolving clinical medicine through advancing research in clinical pharmacology and understanding of disease pathology.

As many students opt for a career in clinical specialties rather than basic sciences, a deficiency of teaching faculty in many medical institutes is created ${ }^{8}$, and this issue requires utmost attention, as $38.1 \%$ of respondents showed disinterest for basic sciences in the study which still a big number which should not be ignored. Hence, it's important to provide sufficient career counseling for both broad categories of career paths. Study showed no significant differences with nearly similar responses among variables regarding their attitudes and perception about a career in basic science. However, majority of the students in this survey from both disciplines agreed that there is lack of awareness among students about basic science career and there are limited post-graduation/employment options in basic sciences. In findings of a similar study, dental students reported being less aware of the variety of career options and were less interested in research related fields. ${ }^{21}$ This could be linked to students from our study being unfamiliar about further studies and employment options in this specialty. In a similar research, dental students reported insufficient knowledge and awareness about research related career, as most perceive clinical experience being more essential than research. ${ }^{22}$ In this part of the world, dental science students usually perceive that basic medical science careers are only available to medical students, a concept that needs to be redefined.

Respondents from study believed to some extent that basic sciences research is not given as much heed as clinical research which might result in little or no interest in basic sciences careers. Attention given to basic science research at undergraduate level is poor, which needs improvement as it can impact clinical skills as well as career choices later on. ${ }^{23}$ As in a survey of 2019, basic science was not a preferred career among students as most of them were not satisfied with basic science teaching and did not feel it's relevance to clinical practice. ${ }^{24}$ Similarly, in this study they also felt lack of interest in basic science career is due to no patient interaction in this field which leads to students being more attracted to clinical sciences. Opportunities should be given to those in basic sciences to have some patient interaction alongside research and academics or take part in clinical researches which might overcome this issue. ${ }^{10}$ Many participants from study population also confessed that they face lack of encouragement from teachers and medical community for pursuing career in basic sciences, an issue that needs consideration. Students believe that a good teaching faculty plays a major role in creating fascination towards basic sciences. ${ }^{25}$ Improvements in respect to awareness about career and post-graduation/employment options should be done. Teachers and fellow educators should work on encouraging and motivating students towards basic science career and more direct clinical role should be incorporated in basic sciences that might attract more professionals towards a career in basic sciences.

\section{CONCLUSION:}

More interest has been observed amongst graduates than in students for basic science career. Involving dental students in this survey augmented this study as their interests and perspectives about a career in basic sciences also came into light. However, majority of students and graduates from both disciplines believed there is lack of motivation and awareness about this career path, limited career and postgraduation options in basic sciences, no patient interaction and pressure from family creates disinterest in this career.

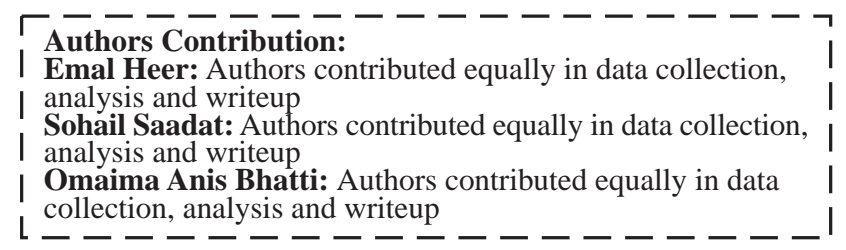

\section{REFERENCES:}

1. Althubaiti S, Althubaiti N. Saudi Medical Students' Interest in Basic Medical Sciences and the Factors Affecting It. Global Journal of Health Science. 2018;10:30. DOI: https://doi.org/ 10.5539/gjhs. v10n4p30

2. Sajadi FS, Borna R, Borna A, Ahmadipour H. Attitude of Kerman dental school students toward their field of study and career future. Int J Dental Sci Res. 2015;3:60-3. DOI: https:// doi.org/10.12691/ ijdsr-3-3-5

3. Khatri R. Basic sciences: an alternative career? Kathmandu Univ Med J. 2013;11(41):78-80.DOI: https://doi.org/ 10.3126/kumj.v11i1. 11033

4. Alawad AA, Khan WS, Abdelrazig YM, Elzain YI, Khalil $\mathrm{HO}$, Ahmed OB, et al. Factors considered by undergraduate medical students when selecting specialty of their future careers. Pan Afr Med J. 2015;20(102). DOI: https://doi.org/ 10.11604/pamj. 2015.20.102.4715 
5. Shah DK, Jha R, Sah A, Sah P, Paudel K, Dhungana G. Students' Attitude and Perception towards Basic Sciences in a Medical School of Nepal: A Cross-sectional Study. Journal of Contemporary Medical Education. 2015;3:1. DOI: https://doi.org/10.5455/jcme.20151125021314

6. Rosyila, Syakurah R. Medical student career choice's determinants in Asia: a systematic review. International Journal of Public Health Science (IJPHS). 2020;9:57-61. DOI: http://doi.org/10.11591/ijphs.v9i1.20400

7. Gupta S, Gupta AK, Verma M, Kaur H, Kaur A, Singh K. The attitudes and perceptions of medical students towards basic science subjects during their clinical years: A crosssectional survey. Int J Appl Basic Med Res. 2014;4(1):16-9. DOI: https://doi.org/10.4103/2229-516X.125675

8. Querido S, van den Broek S, de Rond M, Wigersma L, Ten Cate O. Factors affecting senior medical students' career choice. Int J Med Educ. 2018;9:332-9. DOI: https://doi.org/ 10.5116/ijme.5c14. de75

9. Yamazaki Y, Uka T, Shimizu H, Miyahira A, Sakai T, Marui E. Japanese medical students' interest in basic sciences: a questionnaire survey of a medical school in Japan. The Tohoku Journal of Experimental Medicine. 2013;229(2):129-36. DOI: https://doi.org/ 10.1620/tjem.229.129

10. Javed K, Anwar K, Aamir F. Perception and Interest of Medical Students Regarding Basic Medical Science Subjects. Cell. 2016;322:8400970.

11. de Bruin AB, Schmidt HG, Rikers RM. The role of basic science knowledge and clinical knowledge in diagnostic reasoning: a structural equation modeling approach. Acad Med. 2005;80(8):765-73. DOI: https://doi.org/ 10.1097/ 00001888-200508000-00014

12. Laurie GA, Venkatesh B, Kruger PS, Morgan TJ, Pascoe RL. Basic science research in Australian intensive care practice. Crit Care Resusc. 2008;10(1):52. PMID: 18304018

13. Yograj S, Bhat AN, Gupta RK, Gupta G, Kalsotra L. Role of basic sciences in making of a clinician: Perspectives of medical students from North India. J Educ Health Promot. 2019;8(171). DOI: https://doi.org/10.4103/jehp.jehp_66_19

14. Akhund S, Shaikh ZA, Kolachi HB. Career related choices of medical students from an International Medical College of Karachi, Pakistan. JLUMHS. 2012;11(3):180-84.

15. Zia S, Abbas M, Sulaiman M, Sheikh SM. Career choices of Medical doctors at Graduate level-A Multicenter Study. Pakistan journal of medical sciences. 2017;33(5):1086. DOI: https://doi.org/ 10.12669/pjms.335.12945
16. Biggs JS. Postgraduate medical training in Pakistan: observations and recommendations. J Coll Physicians Surg Pak. 2008;18(1):58-63. DOI: https://doi.org/ 01.2008 /jcpsp.5863

17. Al-Fouzan R, Al-Ajlan S, Marwan Y, Al-Saleh M. Factors affecting future specialty choice among medical students in Kuwait. Medical education online. 2012;17(1):19587. DOI: https://doi.org/10.3402/meo.v17i0.19587

18. Yamazaki Y, Uka T, Marui E. Professional fulfillment and parenting work-life balance in female physicians in Basic Sciences and medical research: a nationwide cross-sectional survey of all 80 medical schools in Japan. Human resources for health. 2017;15(1):65. DOI: https://doi.org/10.1186/s12960017-0241-0

19. Yamazaki Y, Fukushima S, Kozono Y, Uka T, Marui E. Exploring Attractiveness of the Basic Sciences for Female Physicians. The Tohoku Journal of Experimental Medicine. 2018;244(1):7-14. DOI: https://doi.org/10.1620/tjem.244.7

20. Knevel RJ, Gussy MG, Farmer J, Karimi L. Nepalese dental hygiene and dental students' career choice motivation and plans after graduation: a descriptive cross-sectional comparison. BMC medical education. 2015;15(1):219. DOI: https://doi.org/ 10.1186/s12909-015-0500-5

21. Crossley ML, Mubarik A. A comparative investigation of dental and medical student's motivation towards career choice. British dental journal. 2002;193(8):471-3. DOI: https://doi.org/ 10.1038/sj.bdj.4801599

22. Alhazzazi TY, Bogari DF, Alzebiani NA, Hazzazi LW, Abed $\mathrm{HH}, \mathrm{Al}-\mathrm{Hazmi}$, et al. Research Interest Assessment Among Dental Students at King Abdulaziz University Faculty of Dentistry. 2016. DOI: https://doi.org/ 10.15226 /jdodt. 2016.00160

23. DeFranco DB, Sowa G. The Importance of Basic Science and Research Training for the Next Generation of Physicians and Physician Scientists. Molecular Endocrinology. 2014;28(12): 1919-21. DOI: https://doi.org/10.1210/me.2014-1343

24. Getu AA. Basic Science courses in the eyes of Medical Students during their clinical study years at University of Gondar. 2019. DOI: https://doi.org/10.7439/ijbar.v10i10.5275

25. Abd-Rabo M, El-Belbasy R, Abo-Elmagd EK. Medical Students' Attitude and Perception towards Basic Medical Sciences in the Faculty of Medicine for Girls, Al-Azhar University: A Study Prior to the Integrated Program. The Egyptian Journal of Hospital Medicine. 2018;70(12):204350. DOI: https://doi.org/10.12816/0045026 